\title{
Transmediação do livro-AlFabeto HoJe SINTO-ME...: UMA LEITURA COMPARATIVA DE DUAS EDIÇÕES
}

TRANSMEDIACIÓN DEL LIBRO-ALFABETO HOJE SINTO-ME...: UNA LECTURA COMPARATIVA
DE DOS EDICIONES

Transmediating alphabet book Hoje SinTo-ME... A comparative reading OF TWO EDITIONS

\section{Inês Costa}

Mestre em Estudos Editoriais pela Universidade de Aveiro. Doutoranda em Estudos Literários, Universidade de Aveiro, Portugal.

Departamento de Línguas e Culturas Universidade de Aveiro, Campus Universitário de Santiago 3810-193

Aveiro, Portugal.

inesmmcosta@ua.pt

\begin{abstract}
RESUMO
Partindo do pressuposto de que todas as opções tomadas durante o processo de criação e editorial trabalham em conjunto para transmitir significados (Sipe, 2001), sugere-se que duas edições diferentes da mesma obra possam proporcionar experiências de leitura diferentes. Ao comparar as publicações portuguesa e de língua inglesa do livro-alfabeto Hoje Sinto-me..., de Madalena Moniz, analisando as componentes textual, de ilustração e de arquitetura do objeto, com especial ênfase nos elementos paratextuais, concluiu-se que a primeira privilegia a dimensão estética e a segunda a vertente educativa. Para além das opções editoriais, as variações introduzidas pela autora contribuíram, igualmente, para criar perceções globais marcadamente distintas, ao ponto de poder inferir-se que a própria personalidade do protagonista terá sofrido alterações.
\end{abstract}

Palavras-chave: literatura comparada; transfers culturais; literatura infantil; livro-álbum; Madalena Moniz

\section{RESUMEN}

Partiendo de la premisa de que todas las elecciones que se hacen durante el proceso de creación editorial trabajan en concierto para la transmisión de significados (Sipe, 2001), se propone que dos ediciones distintas de una misma obra pueden proporcionar experiencias de lectura distintas. Al comparar las publicaciones en lenguas portuguesa e inglesa del libro-alfabeto Hoje Sinto-me..., de Madalena Moniz, y analizar los componentes textual, de ilustración y de arquitectura del objeto, con énfasis especial en los elementos paratextuales, concluimos que la primera privilegia la dimensión estética mientras que la segunda se centra en la corriente educativa. Más allá de las selecciones editoriales, las variaciones introducidas por la autora contribuyeron, igualmente, a crear percepciones globales marcadamente distintas, hasta el punto en que puede inferirse que la personalidad misma del protagonista habrá sufrido alteraciones.

Palabras clave: literatura comparada; transfers culturales; literatura infantil; libro álbum; Madalena Moniz 


\section{Abstract}

Based on the premises that any choice made throughout the process of editorial creation works in tune to deliver meaning (Sipe, 2001), we put forward that two separate editions of a same book can deliver distinct reading experiences. When we compared the publications in Portuguese and English language of Madalena Moniz' alphabet book Hoje Sinto-me..., analyzed their textual, illustration, and object architecture components, emphasizing on paratextual elements, we came to the conclusion that the first edition favors the aesthetic dimension, while the second one focuses in an educational approach. Beyond editorial choices, variations introduced by the author herself contributed also to create markedly different global perceptions that led us to conclude that even the main character's personality would have endured changes.

Keywords: comparative literature; cultural transfers; children's literature; picture book; Madalena Moniz. 


\section{Introdução}

Uma das principais características que diferenciam o livro-álbum de outros tipos de publicações é o protagonismo partilhado entre texto e imagem. Segundo Sipe (1998, 2001), ambas as componentes têm o potencial de produzir significados e trabalham em conjunto para criar uma unidade artística que alcança um resultado muito superior à soma das partes. Havendo primazia de uma delas, esta recai, indiscutivelmente, sobre a ilustração (Bosch, 2007); em última instância, o texto pode nem chegar a existir, já que a sua ausência «não implica ausência de discurso e de narração» (Ramos, 2011, p. 29). Ramos (2011, pp. 29-30) apresenta uma proposta para as diferentes tipologias do livro-álbum tripartindo-os em narrativos (com ou sem texto, em prosa ou em verso), poéticos ou líricos e portefólio, documentário ou catálogo, havendo, nestes últimos, adição de informação a cada virar de página sem, necessariamente, uma sequência de causalidade. É nesta categoria que se inserem os livros-alfabeto ${ }^{1}$, como o que se pretende analisar ao longo deste ensaio.

Hoje Sinto-me..., com texto e ilustrações da autoria de Madalena Moniz, é um abecedário de emoções e foi distinguido com uma menção especial na categoria Opera Prima, na Feira do Livro de Bolonha em 2015. Figura, igualmente, na lista dos livros recomendados pelo Plano Nacional de Leitura (PNL), na categoria de Educação Pré-Escolar. Anteriormente, a autora tinha recebido com o seu álbum de estreia, Silvio, o Domador de Caracóis (2010), um destaque especial do júri do Prémio Nacional de Ilustração, o que reforça a pertinência do estudo do seu trabalho. Assim, neste artigo, far-se-á uma caracterização aprofundada da obra Hoje Sinto-me..., não só ao nível de texto e ilustração, como da própria construção e arquitetura do objeto-livro, dando especial atenção aos diferentes elementos paratextuais que

1 Silva e Martins (2016) propõem uma categorização do livro-alfabeto infantil a partir da análise de vários livros nacionais. Hoje Sinto-me..., de Madalena Moniz, faz parte do corpus desse estudo. contribuem para a comunicação de significados, do tamanho e formato, à capa, contracapa, guardas, folhas de rosto, entre outros. Elaborar-se-á, igualmente, um estudo comparativo entre a edição portuguesa e a edição em língua inglesa (comercializada no Reino Unido e nos Estados Unidos da América) ${ }^{2}$, sublinhando as principais diferenças e o modo como estas interferem na perceção geral da obra.

Os primeiros esboços de Hoje Sinto-me... surgiram no último ano da formação de Madalena Moniz em Ilustração na Creative Arts School (University of the West of England), em Bristol, onde frequentou um seminário com Martin Salisbury. Nessa altura, o projeto intitulava-se Manu Is Feeling... From $A$ to $Z$ e foi considerado suficientemente original para ser citado como caso de estudo por Salisbury, no seu livro Children's Picturebook: The Art of Visual Storytelling (2012). Os pressupostos fundamentais da obra já se encontravam definidos (Salisbury \& Styles, 2012, pp. 62-65), Madalena Moniz desejava criar um abecedário de sentimentos, em que figurava somente uma personagem, inspirada no seu irmão Manuel, presente em todas as páginas e vestida sempre do mesmo modo. O livro vive da ilustração de padrões, da relação entre o padrão da letra, a palavra sugerida e a ilustração na página de verso e do tom delicado, evidente em toda a obra e reforçado através de várias técnicas que serão analisadas adiante. A opção pelo livro-álbum, e mais especificamente pelo livro-alfabeto, atraiu a autora pela possibilidade de poder concentrar-se em cada dupla página sem os espartilhos de uma estrutura narrativa, desafiando-a, simultaneamente, a prender a atenção do leitor sem o recurso a uma história sequencial (Salisbury \& Styles, 2012, p. 63).

\section{Hoje Sinto-me...}

A edição portuguesa de Hoje Sinto-me... é apresentada num formato retangular de orientação vertical. Esta orientação, especialmente acentuada,

2 Para simplificar, esta edição será referida como a edição inglesa. 
dado a dimensão vertical ser pouco menor do que o dobro da dimensão horizontal $(26,7 \times 17,4 \mathrm{~cm})$, permite uma representação mais focada em personagens humanas, aumentando a identificação do leitor com a personagem (Sipe, 2001, p. 25). Ao mesmo tempo, como veremos, este formato contribui para a construção do significado da obra ao acentuar algumas das características da personagem sugeridas pela experiência global da leitura.

A capa (Figura 1, à esquerda), cartonada, como é habitual no tipo de publicação livro-álbum (Ramos, 2011 , p. 18), apresenta alguma textura, o que possibilita o envolvimento de outros sentidos do leitor para além da visão - neste caso, o tato (e mesmo a audição) - e convida à interação. $\mathrm{O}$ efeito mate, assim como a cor de fundo, branco-creme e não branco, propicia uma relação de intimidade, por oposição ao brilho que atrai para a superfície e desvia a atenção dos pequenos detalhes (Nodelman, 1988, p. 47). Ao nível da representação visual, a capa é sóbria, o título surge pintado num mural, aparentemente pela criança que está de cócoras no canto inferior direito a terminar as reticências. Este é, assim, o primeiro contacto do leitor com o protagonista, cumprindo-se, deste modo, uma das possíveis funções da ilustração da capa, a de apresentar e facultar traços prévios de caracterização das personagens (Mota, 2016, p. 143). A quebra do título em múltiplas linhas não cumpre as regras de translineação da língua portuguesa, sugerindo liberdade e rebeldia artística. O nome da autora surge escrito num tipo de letra aparentemente desenhado à mão (repare-se que letras iguais são grafadas de maneira diferente), uma característica que terá continuidade no miolo. Na contracapa (Figura 1, à direita), da mesma cor da capa, aparecem desenhadas as letras do abecedário através da utilização de diferentes padrões. São os mesmos padrões que existem no interior do livro, pelo que a contracapa é o fechar de um ciclo, promovendo o reconhecimento das letras e convidando a um jogo de memória visual com a associação das diferentes letras e padrões às emoções sugeridas pela autora.

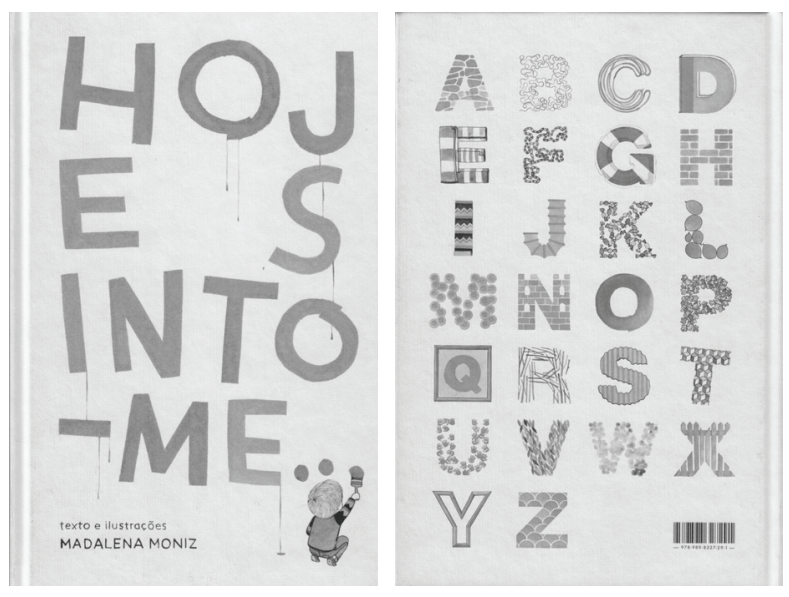

Figura 1 Capa e contracapa de Hoje Sinto-me...

Antes da análise dos restantes elementos paratextuais, façamos um apontamento sobre o título: Hoje Sinto-me... A opção inicial, Manu Is Feeling..., reportava diretamente ao estado emocional da personagem, Manu, reservando ao leitor o papel de observador. Com Hoje Sinto-me... não fica claro se os sentimentos pertencem, de facto, ao menino tímido de calças castanho-claras e camisola estampada ou se os leitores podem apoderar-se deles. Esta alteração, inteligente do ponto de vista editorial, aumenta a sensação de proximidade e promove a identificação, para além de estabelecer um novo nível de interação no final do livro, como daremos conta.

Na opinião de Sipe e McGuire, as guardas marcam «um movimento entre o espaço público da capa e o mundo privado do livro» (2006, p. 3). Nesta edição, as guardasiniciaise finais são iguais e estão totalmente preenchidas por um padrão que será repetido na ilustração associada à letra B. Nas categorias abrangentes sugeridas por Sipe e McGuire (2006, pp. 10-15), estas enquadram-se na de guardas iniciais e finais iguais e ilustradas. Mais especificamente, de acordo com a proposta de Ramos (2007, p. 224), podemos identificá-las como guardas com motivo padronizado, pois nelas «surge a repetição de um motivo relacionado com a ilustração e [...] possuem uma funcionalidade decorativa » (Ramos, 2007, p. 224). O elemento paratextual seguinte, a ficha técnica, 
utiliza o mesmo tipo de letra caligrafado que indicara a autoria do livro e, na folha de rosto, volta a surgir o título, com grafismo idêntico ao da capa, porém houve um avanço temporal: o menino terminou as reticências e está agora em bicos dos pés a pintar «de $\mathrm{A}$ a $\mathrm{Z}$ ». Se até ao momento o leitor não tinha olhado para a contracapa, só agora se apercebe da sugestão de um abecedário. Neste sentido, a informação vai sendo adicionada a cada virar de página, aumentando as expectativas. Antes de analisar o conteúdo e a forma como é apresentado, damos conta do tipo de papel utilizado que, sendo mate, ligeiramente texturado e de cor branco-creme, promove, mais uma vez, uma leitura íntima, de proximidade com a narrativa. A elevada gramagem acentua a qualidade da edição.

Cada uma das vinte e seis duplas páginas que constituem o miolo do livro é dedicada a uma das letras do abecedário e a um tipo de sentimento ou emoção. A estrutura é igual em toda a obra (Figura 2); na página do lado esquerdo, em fundo branco, é desenhada a letra do abecedário através da utilização de um padrão e, em baixo, o sentimento, cuja primeira letra faz correspondência, surge escrito com a fonte caligrafada a que já fizemos referência. A opção pelo fundo branco é inteligente, pois a sensação de vazio que provoca faz com que a letra e o sentimento sobressaiam na página; o mesmo efeito é produzido pelo posicionamento, centrado horizontalmente. Na página do lado direito, figura a ilustração, quase sempre até ao corte de página. O padrão utilizado para desenhar a letra está de algum modo relacionado com a ilustração, ou através de repetição - como, por exemplo, no caso da letra A (Figura 2) ou H, em que se repete o revestimento das paredes - ou através de algum tipo de associação - na letra N, a ilustração mostra o menino com uma coroa na cabeça, a espreitar pela cortina de um teatro; o padrão da letra tem recortes que fazem com que esta se assemelhe a um castelo. As associações podem ser mais ou menos óbvias e, enquanto exigem a atenção do leitor para identificá-las, favorecem a ludicidade.

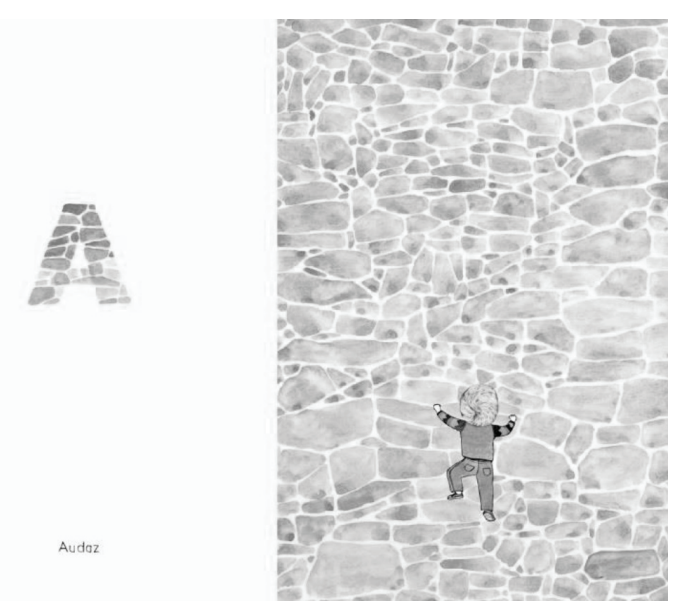

Figura 2 Exemplo de uma dupla página (letra A)

As ilustrações merecem uma análise atenta. As cores, os materiais e as várias técnicas utilizadas remetem para um ambiente delicado que é consonante com o que se antevê da personalidade do protagonista. Assim, as cores são maioritariamente quentes, em tons pastéis onde sobressaem os castanhos, os laranjas e o vermelho claro e esbatido. Estas cores são, inclusivamente, utilizadas no vestuário do protagonista, que se repete ao longo de todo o livro. Esporadicamente, aparecem matizes azulados associados a ambientes aquáticos. Quando o padrão não ocupa a totalidade da página, os fundos são geralmente brancos, transmitindo a ideia de dia, de claridade. A autora recorre ao preto, ainda que poucas vezes - nas letras $\mathrm{C}$ e $\mathrm{H}$-, para transmitir profundidade ou a presença de algo desconhecido, que se situa na sombra. Os materiais utilizados, a aguarela e a tinta da china, reforçam, novamente, a perceção de suavidade e serenidade. Além disso, a aguarela cria uma atmosfera impressionista, evocativa e sugestiva (Sipe, 2001, p. 32), o que se adequa perfeitamente à tentativa de representar algo tão difícil de concretizar como os sentimentos e as emoções. Também a imprecisão do traço delicado, as linhas muito finas e a ausência de contornos contribuem para a perceção de suavidade.

A análise dos contornos é particularmente interessante, uma vez que, quando estes existem, são utilizados com um propósito bem definido. Por exemplo, nas ilustrações referentes às letras $\mathrm{D}$ e E, os 
elementos que são contornados a preto, com tinta da china, são os que estão à superfície, estando os restantes debaixo de água. Note-se, igualmente, que a maioria das letras desenhadas com padróes na página esquerda não apresenta contornos. As exceções, como a letra $S$, justificam-se pelas suas características específicas: neste caso, o contorno acentua a textura ondulada de uma chapa de metal. Esta textura aparente é sugerida em grande parte das ilustrações. A própria técnica utilizada, a pintura a aguarela, permite criar subtis diferenças na tonalidade do mesmo objeto produzindo a ilusão de tridimensionalidade - veja-se, a título de exemplo, a parede de pedra na ilustração da letra A (Figura 2) - , mas a autora serve-se também de sombras para criar um efeito semelhante - atente-se na cortina do teatro, na letra N. Do mesmo modo, os traços muito finos contribuem para a ilusão de textura, ajudando, por exemplo, a representar os veios da madeira ou cada fio do cabelo louro da personagem.

O estudo das perspetivas e posicionamentos revela que, na maioria dos casos, a personagem é vista à distância, ocupando um espaço muito reduzido na página que é preenchida quase na totalidade pelo padrão. Esta opção, a perspetiva ligeiramente picada, que coloca o leitor a um nível superior, e ainda o formato da publicação, marcadamente vertical, acentuam a pequenez do protagonista (no que diz respeito à sua estatura). Repare-se, no entanto, que o facto de a criança parecer pequena não significa que ela não seja o foco principal da ilustração. $\mathrm{Na}$ realidade, a repetição de um padrão faz realçar aquilo que não é padrão, ou seja, a personagem. Ademais, esta aparece quase sempre centrada horizontalmente na página, o que favorece o seu destaque. A escolha do formato vertical revela-se, mais uma vez, inteligente. Conforme exposto, é o formato ideal para sublinhar características de personagens humanas, sobretudo se for somente uma personagem, como é o caso; mas, além disso, permite dar ênfase ao protagonista de um modo que não seria possível se se recorresse a um formato quadrado ou retangular horizontal: numa visão panorâmica, e imaginando que se mantinham as proporções da criança, esta pareceria não apenas pequena, conforme pretendido, mas perdida; um cenário amplo acabaria por engoli-la. Assim, o seu protagonismo é evidente e realçado, ainda que a sua pequenez também seja. À sugestão de uma estatura reduzida junta- se a sugestão de uma certa fragilidade associada à personagem que resulta dos materiais e técnicas de pintura utilizados, como referimos, mas muito do seu posicionamento frequente na metade inferior da página (cf. Sipe, 2001, pp. 29-30) e da tal perspetiva afastada e ligeiramente picada, que, como se não bastasse, coloca o leitor numa posição de observador, alimentando o distanciamento entre ele e a criança que vê retratada, como se não pudesse ajudá-la ou interagir com ela.

Esta ideia de isolamento, quer em relação ao leitor quer em relação a outras personagens, está presente em todo o livro, mas acaba por ser sintetizada na ilustração referente à letra Q. A página encontra-se preenchida com dezenas de molduras, que enquadram fotografias do protagonista em várias idades, desenhos que se imagina que tenha feito ou as suas mãos e pés marcados com tinta em telas ou folhas de papel. Estes elementos acentuam a centralidade da personagem, o quanto é importante ou «Querido», como refere a legenda, mas, simultaneamente, ao retratarem a sua infância, denotam a ausência de outras crianças em seu redor. Nos retratos desta ilustração, trinta e um ao todo, o protagonista aparece acompanhado somente duas vezes: uma abraçado a um cão e outra num desenho que terá feito da família, possivelmente com o pai e a mãe ou uma irmã mais velha.

Ainda sobre a relação entre a perspetiva adotada e o modo como esta cria perceções sobre o tamanho ou a personalidade da criança, sublinhamos algumas variações à perspetiva dominante já referida. É o caso da letra E, em que a perspetiva passa a ser de cima para baixo e a personagem surge quase ao centro da página, a ocupar mais espaço do que é habitual. Este ponto de vista, a ilusão do protagonista parecer maior e a expressão de serenidade no seu rosto contrastam com a insegurança e apreensão que parecem tomar conta dele em 
outras representações. Na ilustração que acompanha a letra $\mathrm{K}$, por exemplo, a perspetiva do leitor é igualmente de cima para baixo, porém o facto de a personagem ocupar menos espaço na folha e estar completamente rodeada de papéis de rebuçados faz com que pareça mais pequena. A ilustração referente à letra $\mathrm{M}$ cria um paradoxo interessante. Por um lado, o protagonista está centrado na página e há um close-up que o torna maior, por outro, o facto de estar dentro de um bolso de camisa e de ser do tamanho de uma caneta, assim como a presença da legenda «Minúsculo», sublinham a sua estatura reduzida. Neste caso concreto, a perspetiva e o posicionamento na página são vencidos pelos outros elementos de representação, sobrepondo-se a ideia de pequeno, que começa a parecer indissociável da de frágil. A ilustração associada à letra X, com a legenda «X. L.», teria, necessariamente, de contrastar com as restantes. Aqui, a perspetiva é fechada, a personagem ocupa uma porção significativa da página e parece gigante quando comparada com as casas que a rodeiam. A postura corporal - os punhos cerrados na cintura, lembrando um super-herói, e o olhar direcionado para baixo - reforça a perceção de estatura elevada, no entanto o facto de não podermos observar a expressão facial impede-nos de aferir como é que o protagonista se sente nesta situação, se apreensivo como quando surge representado como sendo pequeno, se corajoso e confiante como a postura dos braços sugere (a propósito desta postura, veja-se o modo como contrasta com a da ilustração correspondente à letra I, em que surge representado com as mãos nos bolsos e se sente «Invisível»).

A ilustradora imprime variedade nas perspetivas ao representar a criança vista de frente ou de costas (na maioria das situaçóes), mas também de cima (como foi referido) ou por vezes de perfil ou a três quartos. Ainda que esteja quase sempre de pé, em certas ilustrações aparece sentada, deitada, debruçada sobre um buraco, ou de gatas, no chão. A riqueza que estas opções oferecem ao conjunto da obra é complementada com a sugestão de movimento, visível, nomeadamente, na ilustração referente à letra $\mathrm{A}$
(Figura 2), com a personagem a trepar uma parede de pedra; nas letras D e G, com a representação da ondulação marítima; na letra L, em que se imagina que um conjunto de balóes eleva o menino no ar; na letra $R$, em que este salta para tentar apanhar o papagaio que ficou preso na copa de uma árvore; na letra W, voando ao lado de um bando de cisnes; ou na letra $\mathrm{O}$, em que a metade da página pintada e a metade por pintar e a expressão corporal do protagonista sugerem o movimento descendente do rolo com tinta. Destaca-se a ilustração que acompanha a letra $\mathrm{E}$, em que o ondulado dos traços insinua o movimento da água da piscina, ainda que a personagem esteja parada, a boiar, e a ilustração da letra Z, em que as meias circunferências se transformam gradualmente em pássaros a voar.

Uma nova dimensão é acrescentada a partir de uma referência intertextual. $\mathrm{Na}$ ilustração referente à letra $\mathrm{D}$, a personagem lê, deitada de barriga para baixo, em cima de uma cama que flutua no mar que ocupa a totalidade da página. Ao lado, uma baleia gigante está submersa com a cauda de fora - este posicionamento infere-se a partir das cores (branco para a cauda e tons de azul mais claros para a parte do corpo submersa) e do contorno fino a preto, como já foi referido. Esta referência óbvia a Moby Dick, de Herman Melville, reforçada pelo facto de a letra $\mathrm{D}$, desenhada na página do lado esquerdo, tomar a forma de um livro, é sobretudo percebida por adultos. Esta acaba por ser uma característica pós-moderna dos livros-álbum, que, comummente, criam uma ponte com outras obras (literárias, artísticas, cinematográficas, etc.), proporcionando um jogo de adivinhação aos leitores sempre que estes captam as intertextualidades, nem sempre evidentes (Nikolajeva, 2008, pp. 67-68). Esse jogo estende-se aos adultos que acompanham a leitura das crianças, muitas vezes com referências que só eles poderão entender. Este piscar de olhos a dois públicos-alvo - adultos e crianças - é cada vez mais vincado, tornando-se cada vez mais comum identificar livros-álbum que podem classificar-se como crossover (Beckett, 2009, 2012; Ramos, 2011, p. 27). 
Há um outro aspeto que merece um apontamento, pela forma como pode contribuir para a perceção da personalidade da criança e da tranquilidade do ambiente envolvente, que é a insistência na representação de elementos orgânicos. Estes depreendem-se da repetição da presença de árvores (em vários elementos como folhas, galhos, ou na sugestão de uma floresta, que surgirá ao completar o puzzle que ilustra a letra P), ou de madeira de um modo geral (nas molduras, no soalho do teatro ou da ilustração da letra $\mathrm{F}$ ou na cerca que molda a letra $\mathrm{X}$ ), e da introdução de alguns padrões que sugerem ambientes aquáticos. Esta alusão a uma vertente mais orgânica justifica, novamente, a escolha de um papel mate, ligeiramente texturado e de cor branco-creme, como sendo reciclado, assim como a predominância dos tons acastanhados, acompanhados a espaços de verde.

Depois de analisada a componente imagética da obra, debruçamo-nos agora sobre o tipo de emoções e sentimentos a que aludem as vinte e seis palavras que constituem a componente textual e sobre a forma como acrescentam significado à globalidade da experiência de leitura. A escolha de termos como «Baralhado», «Invisível», «Leve», «Nervoso», «Minúsculo» ou «Vulnerável» sublinha a fragilidade que já havíamos associado à personagem a partir das várias técnicas de ilustração, nomeadamente os materiais utilizados, as perspetivas e o posicionamento na página. Noutras situações, essa fragilidade só é percetível perante a análise conjunta de texto e imagem. É o caso de «Forte», um adjetivo quase antónimo de frágil; porém, a ilustração indica que não é exatamente o protagonista que é forte, mas sim a sua sombra projetada, que aumenta desmesuradamente de tamanho. «Audaz», «Curioso»e «Heroico» sugerem atividade e as imagens corroboram essa ideia, mostrando a personagem a trepar uma parede de pedra (ainda que, novamente, as técnicas utilizadas - a aguarela, as formas mais arredondadas e a ausência de contorno - não a tornem especialmente ameaçadora), a espreitar para dentro de um buraco ou a empoleirar-se numa escada comprida para socorrer um animal. Esta imagem de um rapaz sensível e meigo, heroico ao ponto de subir uma escada com várias vezes o seu tamanho para salvar um animal, é transmitida igualmente pelos adjetivos «Genuíno»e «Querido». A audácia, curiosidade e heroísmo não refutam, ainda assim, a perceção de esta ser uma criança calma e sossegada, quase sempre solitária, como refletem os adjetivos «Distante», «Espacial», «Jupiteriano», «Paciente» ou «Sozinho». O adjetivo «Revoltado» parece destoar da personalidade traçada até agora. Todavia, uma análise atenta à ilustração revela mais um sentimento de frustração pela perda do papagaio de papel do que uma revolta que implique irritação, berros ou choro. De facto, o mais surpreendente neste livro é a sensação constante de estar diante de uma criança incapaz de se zangar ou fazer birras.

Por fim, houve letras que conduziram a opções pouco consensuais. Seria, indiscutivelmente, difícil encontrar adjetivos em português a começarem por $\mathrm{K}, \mathrm{W}$ e $\mathrm{Y}$; nem mesmo o dicionário Houaiss retorna termos que pudessem, pelo menos, pertencer ao vocabulário infantil mais comum. Talvez não fosse de descartar a hipótese de não incluir estas letras, evitando opções questionáveis como $\ll \mathrm{K}$. O.», «Wireless», mas, sobretudo, «Y», que não tem qualquer significado - em que contexto poderia o leitor dizer «Hoje sinto-me $\mathrm{Y}$ »? Em todo o caso, as ilustrações que acompanham estas letras atribuem-lhes um significado e o leitor pode acabar por ignorar que $Y$ é somente uma letra, não um sentimento ou emoção, e focar-se na atividade de uma criança a fazer o pino com as pernas abertas, em forma de Y. Ainda assim, a perda da componente textual impede a riqueza do confronto entre texto e imagem presente nas restantes páginas do livro. Do mesmo modo, para as letras $\mathrm{X}$ e Z, não seria complicado selecionar adjetivos em português que substituíssem a expressão $\ll X$. L.» ou a onomatopeia «Zzzz». Parece ser possível intuir que sempre que houve um conflito entre imagens e palavras, as primeiras saíram vitoriosas sobre as segundas, perdendo-se a oportunidade de 
o leitor poder usufruir das máximas capacidades das duas componentes ou, tanto pior, do efeito potenciador da sua conjugação.

Depois das vinte e seis páginas duplas, o livro termina com uma proposta de atividade. As perguntas «E tu? Como te sentes?», escritas com recurso à caligrafia usada ao longo da publicação e ilustradas com um lápis e um apara-lápis, são seguidas de vinte e seis linhas deixadas em branco, uma para cada letra do abecedário, a fim de serem preenchidas com as respostas do leitor. Reforçando a componente artística, em vez de simples traços a direito, as linhas são onduladas, tracejadas, aos ziguezagues, formadas por bolinhas, entre outros, sempre desenhadas à mão.

Referimos que uma das características fundamentais dos livros-álbum do tipo portefólio, documentário ou catálogo é a inexistência de uma sequência que relacione páginas contíguas. Em última instância, podem ser retiradas ou adicionadas páginas ou alterada a ordem da paginação sem que isso altere a perceção global da obra (Ramos, 2011 , p. 34). Neste caso, é evidente que existe a sequência natural do abecedário e a impossibilidade de acrescentar ou omitir uma letra, no entanto as ilustrações em si não sustentam uma sequência narrativa. Visualizar o livro do início para o fim, de trás para a frente ou saltando aleatoriamente de página em página não afeta a experiência de leitura. $\mathrm{O}$ mesmo não aconteceria se existisse, por exemplo, uma sequência temporal - se houvesse uma alteração progressiva do dia para a noite - ou se as técnicas de ilustração imprimissem uma gradação de cores a cada virar de página ou uma mudança de perspetivas que aproximasse ou afastasse cada vez mais o leitor; nessas situações, seria inevitável que a expectativa e a tensão do leitor aumentassem a cada página virada. De qualquer modo, o facto de não haver uma sequência não impede que o livro forme uma unidade portadora de um significado que só se constrói com a interpretação da totalidade das ilustrações e respetivas legendas. Neste caso, foi-nos dada a conhecer uma criança, que é amada pela família, que brinca tanto ao ar livre como dentro de casa, que é sensível e sossegada e a quem associamos delicadeza, fragilidade e, inevitavelmente, solidão. E se as atividades que pratica podem ser reveladas pelos momentos que as ilustrações captam, a personalidade que intuímos infere-se, em grande parte, a partir das técnicas utilizadas. Ademais, a própria estrutura do livro, que respeita escrupulosamente a regra de manter a letra do lado esquerdo e a ilustração do lado direito, é uma opção que acarreta significados. O facto de ela ser rígida, cumpridora de regras e não transgressora é consonante com a perceção que criámos da presença desses mesmos traços na personalidade do protagonista. $\mathrm{Na}$ verdade, analisando o conjunto, poderíamos dizer que, se este livro ou o seu protagonista falassem, falariam baixinho e pausadamente.

\section{Today I Feel...}

Para evitar uma repetição estéril, a análise da edição inglesa focará, principalmente, os aspetos que diferem da edição portuguesa. Estas diferenças são evidentes logo a partir da comparação das dimensões dos objetos e dos elementos que ilustram as capas e contracapas (cf. Figura 1 e Figura 3). Ainda que o formato se mantenha retangular de orientação vertical, embora a proporção entre o comprimento e a largura tenha diminuído ligeiramente (29,9 x 19,7 cm), o tamanho do livro na edição inglesa é maior do que na edição portuguesa. A capa, também cartonada, de fundo branco, tem um acabamento liso e semimate e recorre, para efeitos decorativos, à ilustração que no interior aparece associada à letra $\mathrm{O}$, conquanto esta sofra algumas modificações. O menino está de gatas, com duas latas de tinta ao lado - uma azul e uma cor-de-rosa a pintar as suas mãos no chão e a desenhar letras do abecedário. $\mathrm{O}$ título parece, igualmente, ter sido pintado à mão, mas não pela criança, o que se depreende perante a comparação deste traço mais firme com as letras do abecedário que estão a ser desenhadas no instante captado pela ilustração. No canto inferior direito, com um tipo de letra tipografado (por oposição a caligrafado), lê-se «An Alphabet of Feelings» e o nome da autora. 
Estas opções apresentam o livro de um modo muito distinto da edição portuguesa. Em primeiro lugar, há uma preocupação maior em tornar o título perfeitamente percetível, depois, considera-se imperativo reforçar a componente do abecedário - através das letras desenhadas pela criança, A, B, C, D, e do subtítulo - , por fim, embora não possamos afirmá-lo, a utilização do azul e do cor--de-rosa, lado a lado, sugere a adequação do livro para crianças dos dois géneros, porém reforça, simultaneamente, esse binarismo tradicional. $\mathrm{Na}$ lombada, além do nome da autora, do título e do logótipo da casa editora - tal como na edição portuguesa -, vê-se uma pequena imagem do protagonista a voar, pertencente à ilustração associada à letra F. Na contracapa, os editores ingleses, ao contrário dos portugueses, sentiram a necessidade de explicar o conceito do livro; assim, há uma breve sinopse e algumas perguntas dirigidas ao público. Recorre-se novamente a um estilo tipográfico e utilizam-se várias cores que vão do verde-escuro ao azul, passando pelo vermelho, o amarelo e o preto. Tal como na edição portuguesa, repete-se o abecedário, com as letras desenhadas com padrões diferentes. Ainda assim, devido à restante informação na contracapa, este acaba por não ter o mesmo protagonismo.

As guardas são ilustradas, mas diferentes entre si. Nas guardas iniciais, observa-se tiras em tons de verde e azul, de comprimento variável, pintadas num fundo branco, o que nada esclarece acerca do conteúdo do livro e aumenta a curiosidade do leitor. Nas guardas finais, vê-se exatamente a mesma ilustração, mas surge também o protagonista a pintar com um rolo uma das tiras. São, por isso, designadas de «guardas como narrativas embrionárias ou narrativas resumidas», uma vez que «a observação conjunta destes elementos paratextuais permite a perceção de uma pequena história ou episódio» (Ramos, 2007, p. 224). Esta ilustração, incluída na edição portuguesa, não se repete no miolo da edição inglesa, pelo que possibilita o enriquecimento da experiência de leitura ao acrescentar uma micronarrativa.
A folha de rosto ocupa a dupla página e está ilustrada com quadros com todas as letras do abecedário menos o Y, que é representado pelo protagonista a fazer o pino. Já tínhamos deparado com esta ilustração na edição portuguesa, no entanto ela não existe na edição inglesa, pelo que, a contar com as guardas, pode dizer-se que os paratextos oferecem duas ilustrações adicionais nesta edição. Da folha de rosto, para além da ilustração, constam as informações que já haviam sido visualizadas na capa - nome do livro, da autora, subtítulo - e a chancela editorial. Assim, volta a ser reforçada (duplamente) a relevância do abecedário no livro, assim como a figura do protagonista, aqui virado de frente para o leitor.
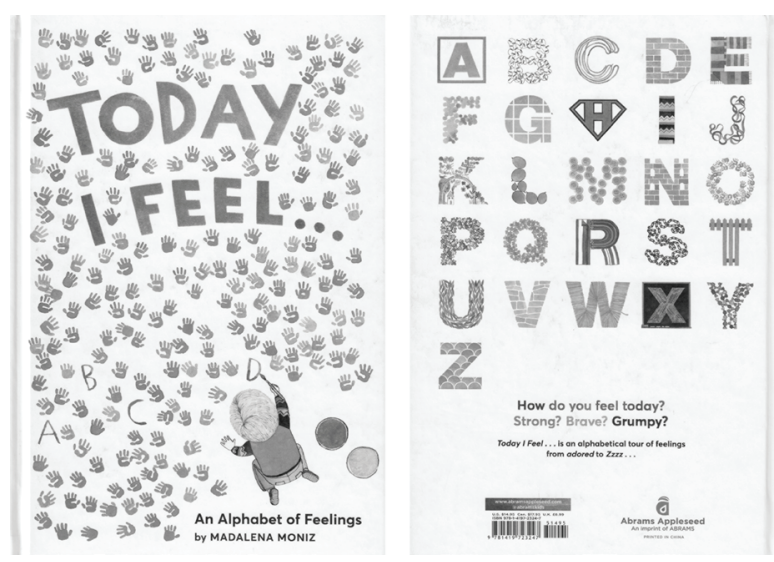

Figura 3 Capa e contracapa de Today I Feel...

$\mathrm{O}$ virar da primeira página na edição inglesa tira proveito de uma certa continuidade que não existe na edição portuguesa; os quadros que encheram a folha de rosto, com o abecedário, são transpostos para a ilustração da letra A, «Adored», mas, desta vez, enquadram os retratos e desenhos do protagonista - que na edição portuguesa ilustravam a letra $\mathrm{Q}$, «Querido». A estrutura das duplas páginas é semelhante nas duas edições, todavia, na versão inglesa, as letras desenhadas com padrões e as legendas foram ampliadas, reforçando o seu protagonismo (Figura 4). Além disso, a legenda passa a ser escrita com um tipo de letra tipografado, o que reduz a harmonia do conjunto; é um tipo de letra 
de formas perfeitas, demasiado carregado, que destoa do traço fino, impreciso e delicado da ilustração e da leveza da aguarela e da tinta da china.

Grande parte das ilustrações é igual nas duas versões, pelo que sublinhar-se-ão somente as diferenças. Na edição inglesa, a claridade dos fundos brancos em ambientes exteriores, que havíamos associado a períodos diurnos e à transmissão de serenidade, não é tão evidente. Logo de início, por exemplo, a ilustração referente à letra B introduz um fundo preto, em representação de uma noite estrelada; para além disso, algumas das ilustrações que remetem para atividades ao ar livre, como nas letras E, H, J e K, mostram um céu em tons de azul e cinzento, cores ligeiramente mais frias que dão menos peso aos tons quentes do conjunto, apesar de estes continuarem a predominar. $\mathrm{Na}$ verdade, este céu azulado ou acinzentado não existia na edição portuguesa; em troca, nesta versão, desaparece o padrão do mar. Esta substituição de representações em tons de azul, associada a outros aspetos como a presença de neve, remete para um clima mais frio na edição inglesa. Refira-se, também, que a alternância da cor do céu entre o azul e o branco nas várias ilustrações que representam atividades no exterior não encontra uma explicação lógica, pelo que o conjunto se torna menos coerente.

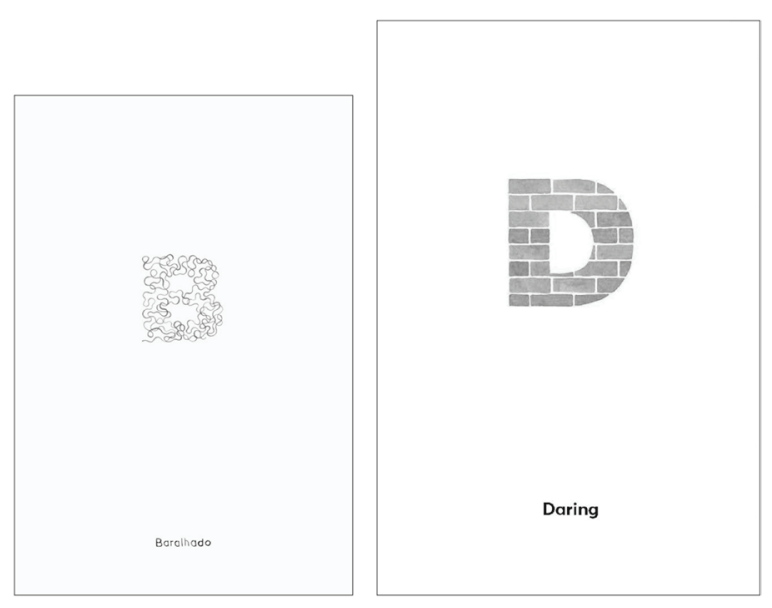

Figura 4 Comparação das páginas de verso das edições portuguesa (à esquerda) e inglesa (à direita)
Em Today I Feel..., o protagonista surge mais vezes acompanhado. Se, na edição portuguesa, isso acontecia somente uma vez e as personagens estavam sentadas lado a lado, porém a uma distância considerável, na versão inglesa, há um beijo anunciado na letra $\mathrm{D}$, o protagonista senta-se ao ombro de um gigante na letra $\mathrm{K}$ (com a legenda «Kind»), há um abraço apertado que se sugere materno na letra $\mathrm{W}$ e outro entre amigos na letra $\mathrm{X}$. Em todos os exemplos existe, assim, o contacto físico que não existira na versão portuguesa. A expressão facial da personagem adquire também outros contornos. Em Hoje sinto-me..., só parecia verdadeiramente feliz a fazer o pino na ilustração referente à letra $\mathrm{Y}$, ou, quando muito, relaxado na piscina na ilustração da letra E. Em Today I Feel..., a tal expressão de felicidade a fazer o pino aparece precocemente, como se viu, na folha de rosto, mas é também visível nas letras $\mathrm{H}, \mathrm{V}$ e W. Ainda que possa, igualmente, ser sugerida pelos braços abertos na ilustração referente ao E e pelo abraço na ilustração a par com a letra X. Esta felicidade parece ser acompanhada por mais intenção de movimento, nomeadamente no salto da ilustração da letra $\mathrm{H}$, reforçado pelo ondulado da capa de super-herói, e, novamente, nos braços estendidos e erguidos em «Excited $»$ e «Victorious respeitantes às letras $\mathrm{E} \mathrm{e}$.

Relativamente às perspetivas adotadas pela ilustradora, nesta edição há uma que destoa das restantes. $\mathrm{Na}$ letra W, há um close-up tão aproximado que a cara do protagonista ocupa quase metade da página. Esta opção faz sentido se atendermos a que ângulos mais fechados promovem a empatia e a criação de emoções (Sipe, 2001, p. 32), reforçando na mente do leitor o aconchego daquele abraço. Não obstante, sublinha-se a dissonância com o restante conteúdo. Outros aspetos permitem aumentar a variedade em Today I Feel..., como é o caso de a personagem aparecer vestida de modo diferente consoante a ocasião. Mantém-se a camisola padronizada e as calças castanho-claras em grande parte das ilustrações, porém o protagonista veste gorro, luvas, cachecol e um casaco 
amarelo num dia de neve (letra E) e um pijama ou uma camisa quadriculada quando fica dentro de casa a olhar para o exterior (letra J). $\mathrm{Na}$ edição portuguesa, aparecia também de pijama numa das ilustrações (letra D), mas, aplicando os mesmos critérios, talvez o vestuário devesse ser diferente na ilustração que remete para o espaço sideral com a legenda «Jupiteriano». Os sentimentos, e por extensão a personalidade, do protagonista também sofrem modificações que promovem a variedade. Por um lado, há um aumento dos estados de espírito considerados negativos como «Grumpy»e «Jealous», por outro, há mais vivacidade em termos como «Daring», «Excited»e «Victorious».

A edição inglesa termina, tal como a portuguesa, com a pergunta «How do you feel today?»; todavia, a escolha do grafismo é diferente. Neste caso, a pergunta, escrita com recurso, pela primeira vez, a um tipo de letra caligrafado - ainda assim, em maiúsculas e indiscutivelmente legível —, surge destacada, ocupando sozinha a página do lado esquerdo. Do lado direito, repete-se a ilustração que tinha sido utilizada na letra $S$, com a legenda «Strong». Assim, à pergunta sucede-se uma sugestão, o que não acontecia na edição portuguesa, que deixava campos abertos para as diferentes possibilidades de resposta. Na dupla página seguinte, o lado esquerdo é ocupado com a ficha técnica e o lado direito com a ilustração do menino a fazer o pino em Y, centrado horizontal e verticalmente na página. Infere-se desta opção a intenção de fechar um ciclo, de «alcançar uma resolução e uma sensação de completude» (Sipe, 2001, p. 37), dado que a mesma ilustração foi utilizada na página de rosto, no início do livro.

\section{Duas edições, duas experiências de leitura}

$\mathrm{Na}$ esteira da afirmação de Sipe de que é importante perceber que todas as escolhas feitas durante o processo de criação e editorial trabalham em conjunto para transmitir um significado e unificar a experiência (2001, p. 27), e diante dos aspetos identificados concernentes às edições portuguesa e inglesa, conclui-se que as experiências de leitura serão necessariamente diferentes, pois estamos diante de duas edições com características diferentes.

Face ao tamanho do objeto, por exemplo, a edição portuguesa, por ser de menores dimensões, é mais intimista, enquanto a edição inglesa será preferível para uma leitura conjunta ou em público (Sipe, 2001, pp. 24-25). Os materiais da capa e miolo da edição portuguesa, pelo seu acabamento mate, textura e cor que foge ao branco puro, criam uma maior interação com o leitor e promovem a intimidade e o envolvimento com a narrativa.

As capas, guardas e folhas de rosto têm diferenças significativas e é importante referir como, regra geral, estes paratextos são mais uma opção editorial do que autoral. A capa da edição inglesa é excessivamente preenchida, não só com ilustrações como com informação. Nesta edição, considera-se extremamente relevante reforçar a centralidade do abecedário, o que é feito novamente na folha de rosto, enquanto na edição portuguesa essa informação não é sequer referida na capa e acaba por ser subtilmente introduzida na folha de rosto, com a frase «de A a $\mathrm{Z}$ », num tamanho de letra bastante inferior ao do título. Esta introdução gradual de informação na edição portuguesa é, mais uma vez, promotora do despertar da curiosidade. Constata-se, igualmente, duas formas diferentes de introduzir o título: na edição portuguesa, há uma maior preocupação com a expressão artística, tornando a capa visualmente mais atrativa com prejuízo da legibilidade das palavras escritas; na edição inglesa, o título, ainda que se procure dar a entender que foi escrito à mão, apresenta um traço certo, sem grandes divergências entre as letras, assegurando a legibilidade. Esta preocupação, que se supõe ser de cariz didático, mantém-se no interior do livro, justificando, assim, a ampliação das letras ilustradas com os padrões e a modificação do tipo de letra para legendar a emoção ou sentimento. Por fim, ainda na capa e lombada, denota-se a intenção, na edição inglesa, de fazer 
sobressair a presença do protagonista - na capa, aparece um pouco ampliado e numa posição ligeiramente mais destacada, na lombada, apenas a edição inglesa reforça essa presença; não será despiciendo que o protagonista seja uma criança, o que automaticamente insere o livro-álbum em questão na categoria de livros infantis. Acrescente-se, também, o facto de, na folha de rosto da edição inglesa, a criança aparecer de frente, havendo uma primeira apresentação ao leitor, enquanto na edição portuguesa, permanece de costas. Mais uma vez, na versão original, há um compasso de espera até ser revelada toda a informação, intrigando o leitor e mantendo-o interessado no desvelar do conteúdo. Faça-se um aparte à criatividade e versatilidade da autora, que, nestas quatro primeiras ilustrações (duas em cada versão), apresenta a personagem de cócoras, em bicos dos pés, de gatas e a fazer o pino. É legítimo questionar se as opções paratextuais da edição inglesa subestimam a capacidade do leitor para interpretar subentendidos e limitam as suas opções, não só pelo exagero de informação paratextual e garantia excessiva de legibilidade já mencionados, que prejudicam a componente artística, como pela sugestão de resposta à pergunta «How do you feel today?»

Ficou demonstrado, igualmente, que Today $I$ Feel... é de certo modo enriquecido e apresenta mais variedade, em diversos aspetos. Refira-se, por exemplo, as ilustrações adicionais nos elementos paratextuais e o facto de, ao longo do livro, serem apresentados mais padrões diferentes - na edição portuguesa, há a repetição do fundo marítimo nas letras D e G e a utilização de quadros nas letras Q e Y. Por outro lado, alguma dessa variedade enfraquece a coerência e consistência da unidade da obra, em aspetos como a representação do exterior, o vestuário da personagem (uma vez que a sua repetição em todas as ilustrações o torna uma marca distintiva) ou mesmo os ângulos de visualização propostos ao leitor. A coerência e a harmonia perdem-se também na alternância entre tipos de letra caligrafados ou tipografados, não sendo fácil de justificar a opção pela pergunta escrita à mão em traço fino nos paratextos finais.
A personagem, por sua vez, tem algo a ganhar com a diversidade. Do ponto de vista relacional, surge mais vezes acompanhada, havendo um contacto físico com outras personagens que não existe na edição portuguesa; além disso, o adjetivo «Sozinho» desapareceu, o que confirma esta perceção. Continua a ser uma criança calma, paciente, serena - uma imagem que dificilmente desapareceria atendendo às técnicas de ilustração - , porém na edição inglesa é mais alegre e transmite mais vivacidade. Essa perceção constrói-se, por exemplo, através do contraste da representação de «Heroico» nas duas versões: na edição portuguesa, o menino está a tentar salvar um animal, todavia a sua expressão corporal indica um movimento lento; na edição inglesa, o protagonista finge ser um super-herói e é representado durante um salto descendente com uma capa a esvoaçar, havendo uma projeção de maior dinamismo. As restantes manifestações de alegria depreendem-se das expressões faciais e corporais já analisadas, mas também da componente textual do livro. No polo oposto, adjetivos que remetem para emoções conotadas negativamente como «Grumpy» e «Jealous» tornam a personagem mais realista (ainda que, tal como «Revoltado», sejam sugeridas de um modo ligeiro), permitindo que esta se mova num espetro mais amplo de estados de espírito.

\section{Considerações finais}

Através da comparação de duas edições diferentes de uma obra, pudemos constatar a relevância dos paratextos e das escolhas editoriais para a perceção global da mesma. Na edição inglesa, há uma maior preocupação com a legibilidade e com o esclarecimento do conteúdo, em prejuízo da componente artística do objeto. Na edição portuguesa, é percetível o privilégio concedido à harmonia da unidade da obra, que se infere, em primeira instância, pela utilização ao longo do livro do mesmo tipo de letra caligrafado e com traço fino e delicado, que, não por acaso, está em harmonia com as técnicas de ilustração. Estas opções indiciam dois modos distintos de olhar para a literatura infantil e a sua comercialização. Face às três vertentes consagradas nos livros para a infância que abarcam leituras plurais - qualidade estética, visual 
e literária, ludicidade e formatividade (Ramos, 2012, p. 18) -, para este caso concreto, o mercado editorial inglês parece valorizar a componente educativa, enquanto o mercado editorial português não abdica da dimensão estética, reconhecendo ao leitor competências de interpretação artística.

As variações introduzidas pela autora na edição inglesa desempenham também um papel fundamental na conceção de diferentes experiências de leitura. A variedade de fundos, a existência de pelo menos uma ilustração com um ângulo muito fechado, a mudança de vestuário, entre outros criam uma nova dinâmica; poderíamos falar numa representação mais rica, porém a perda da harmonia do conjunto não pode ser desprezada. $\mathrm{Na}$ realidade, a delicadeza da aguarela, a placidez das cores pastel ou as formas detalhadamente ilustradas eram totalmente consonantes com uma certa tranquilidade e estatismo, que são quebrados com as variações. $\mathrm{O}$ mais relevante é $d e$ facto o modo como as duas edições transmitem perceções diferentes acerca da criança, como se se tratasse de duas pessoas distintas. Neste caso, não obstante a perda da harmonia do conjunto e da relação estreita entre as técnicas utilizadas e o significado do que é representado, a edição inglesa salvaguarda a verosimilhança ao tornar a personalidade do protagonista mais realista, o que, em última instância, aumenta o sentimento de identificação do leitor. As crianças podem ser sossegadas, pacientes e meigas, mas é também expectável que fiquem rabugentas, que se zanguem ou que chorem de vez em quando.

\section{Referências}

\section{Bibliografia ativa}

Moniz, M. (2014). Hoje Sinto-me.... Lisboa: Orfeu Negro.

Moniz, M. (2017). Today I Feel...: An Alphabet of Feelings. Nova Iorque: Abrams Appleseed.

\section{Bibliografia passiva}

Beckett, S. L. (2009). Crossover fiction. Global and historical perspectives. Nova Iorque: Routledge.

Beckett, S. L. (2012). Crossover picturebooks. A genre for all ages. Nova Iorque: Routledge.

Bosch, E. (2007). Hacia una definición de álbum. Anuario de Investigación en Literatura Infantil y Juvenil, 5, 25-45.

Mota, C. (2016). Viagem exploratória pela atual literatura infantil. Porto: Tropelias \& Companhia.

Nikolajeva, M. (2008). Play and playfulness in postmodern picturebooks. In L. Sipe, \& S. Pantaleo (org.), Postmodern picturebooks: Play, parody, and self-referentiality (pp. 55-74). Oxon e Nova Iorque: Routledge.

Nodelman, P. (1988). Words about pictures. The narrative art of children's picture books. Athens, GA: University of Georgia Press.

Ramos, A. M. (2007). Livros de palmo e meio. Reflexões sobre literatura para a infância. Lisboa: Editorial Caminho.

Ramos, A. M. (2011). Apontamentos para uma poética do álbum contemporâneo. In B.-A. Roig Rechou, I. Soto Lopéz, \& M. Neira Rodríguez (org.), O Álbum na Literatura Infantil e Xuvenil (2000-2010) (pp.13-40). Pontevedra: Edicións Xerais de Galicia.

Ramos, A. M. (2012). Tendências contemporâneas da literatura portuguesa para a infancia e juventude. Porto: Tropelias \& Companhia.

Salisbury, M., \& Styles, M. (2012). Children's picturebooks: The art of visual storytelling. Londres: Laurence King Publishing.

Silva, S. R. da, \& Martins, D. M. (2016). Con letras se hacen palabras: contribuciones para una caracterización del libro-abecedario para la infancia. Elos. Revista de Literatura Infantil e Xuvenil, (3), 143-165.

Sipe, L. R. (1998). Learning the language of picturebooks. Journal of Children's Literature, (24), 66-75.

Sipe, L. R. (2001). Picturebooks as aesthetic objects. Literacy Teaching and Learning: An International Journal of Early Reading and Writing, 6(1), 23-42.

Sipe, L. R., \& McGuire, C. E. (2006). Picturebook endpapers: resources for literary and aesthetic interpretation. Children's Literature in Education, 37(4), 291-304.

How to reference this article: Costa, I. (2019). Transmediação do livro-alfabeto Hoje sinto-me...: uma leitura comparativa de duas edições. Íkala, Revista de Lenguaje y Cultura, 24(3), 575-588. DoI: 10.17533/udea.ikala.v24n03a05 